\title{
Treatment with the C5a receptor antagonist ADC-1004 reduces myocardial infarction in a porcine ischemia-reperfusion model
}

\author{
Jesper van der Pals', Sasha Koul', Patrik Andersson¹, Matthias Götberg ${ }^{1}$, Joey FA Ubachs², Mikael Kanski², \\ Håkan Arheden², Göran K Olivecrona', Bengt Larsson ${ }^{3,4}$, David Erlinge ${ }^{1 *}$
}

\begin{abstract}
Background: Polymorphonuclear neutrophils, stimulated by the activated complement factor C5a, have been implicated in cardiac ischemia/reperfusion injury. ADC-1004 is a competitive C5a receptor antagonist that has been shown to inhibit complement related neutrophil activation. ADC-1004 shields the neutrophils from C5a activation before they enter the reperfused area, which could be a mechanistic advantage compared to previous C5a directed reperfusion therapies. We investigated if treatment with ADC-1004, according to a clinically applicable protocol, would reduce infarct size and microvascular obstruction in a large animal myocardial infarct model.

Methods: In anesthetized pigs $(42-53 \mathrm{~kg})$, a percutaneous coronary intervention balloon was inflated in the left anterior descending artery for 40 minutes, followed by 4 hours of reperfusion. Twenty minutes after balloon inflation the pigs were randomized to an intravenous bolus administration of ADC-1004 (175 mg, $n=8$ ) or saline $(9 \mathrm{mg} / \mathrm{ml}, \mathrm{n}=8)$. Area at risk (AAR) was evaluated by ex vivo SPECT. Infarct size and microvascular obstruction were evaluated by ex vivo MRI. The observers were blinded to the treatment at randomization and analysis.

Results: ADC-1004 treatment reduced infarct size by 21\% (ADC-1004: $58.3 \pm 3.4$ vs control: $74.1 \pm 2.9 \% A A R$, $p=0.007$ ). Microvascular obstruction was similar between the groups (ADC-1004: $2.2 \pm 1.2$ vs control: $5.3 \pm 2.5 \%$ AAR, $p=0.23$. The mean plasma concentration of ADC-1004 was $83 \pm 8 \mathrm{nM}$ at sacrifice. There were no significant differences between the groups with respect to heart rate, mean arterial pressure, cardiac output and blood-gas data.
\end{abstract}

Conclusions: ADC-1004 treatment reduces myocardial ischemia-reperfusion injury and represents a novel treatment strategy of myocardial infarct with potential clinical applicability.

\section{Background}

Reperfusion therapy is the standard treatment of acute myocardial infarction, and restoration of blood flow limits infarct size and reduces mortality. Paradoxically, reperfusion in itself may also cause additional damage to the previously ischemic myocardium, a phenomenon referred to as reperfusion injury [1-3]. The molecular basis for reperfusion injury has not been fully elucidated, but there is evidence for several possible mechanisms of damage including oxidative stress, calcium overload, mitochondrial damage, apoptosis, complement activation

\footnotetext{
* Correspondence: david.erlinge@med.lu.se

'Department of Cardiology, Skåne University Hospital, Lund, Sweden

Full list of author information is available at the end of the article
}

and an inflammatory reaction. One aspect of reperfusion injury is the impairment of microvascular coronary blood flow (microvascular obstruction) seen during reperfusion. The development of microvascular obstruction is a multifactorial process attributable to endothelial damage, thrombus formation, neutrophil aggregation, myocyte swelling, capillary spasm and debris from dying cells [4,5]. Microvascular obstruction has been found to be a strong independent predictive marker of postinfarction complications even after adjustment for infarct size [6].

Complement activation is an early event in cardiac ischemia-reperfusion injury [7], and the activated complement system can induce tissue damage both directly and in-directly [8-10]. Directly, the C5b-9 membrane 
attack complex has cytolytic capacity and has been shown to induce myocardial injury $[11,12]$. Complement cascade products also appear to injure the endothelium leading to a vicious circle of vasoconstriction, microvascular hypoperfusion and apoptosis [13,14]. Indirectly, the activated complement factor C5a stimulates neutrophils by inducing chemotactic migration [15], aggregation $[16,17]$, and release of cytotoxic products such as proteases, elastases and reactive oxygen species that destroy the cell membrane and cause cell death [16-18]. Neutrophils activated by C5a may also contribute to microvascular obstruction by plugging of the microcirculation [19]. Further support for the importance of neutrophils in ischemia-reperfusion injury is offered by studies demonstrating a cardioprotective effect of either depletion of circulating neutrophils or by inhibition of neutrophil function $[17,18]$. For these reasons, neutrophils are thought to be important mediators of cardiac ischemia-reperfusion injury [20].

ADC-1004 is a truncated and mutated form of the Chemotaxis inhibitory protein of Staphylococus aureus (CHIPS) [21-23]. It was developed using FIND ${ }^{\circledR}$, a directed in-vitro evolution technology that mimics the natural process of creating protein diversity through recombination [21]. ADC-1004 binds to, but does not activate, the C5a receptor, thereby acting as an effective antagonist [24]. By intervening directly at the C5a receptor, it offers the advantage of exerting its effect on circulating neutrophils, prior to the arrival of the neutrophils at the infarct area. This could be a key to effective anti-neutrophil treatment of myocardial ischemia-reperfusion injury.

We investigated if treatment with ADC1004, according to a clinically applicable protocol, would reduce myocardial injury in a large animal ischemia/reperfusion model. The primary- and secondary end points were reductions of infarct size and microvascular obstruction relative to the area at risk.

\section{Methods}

\section{Experimental preparation}

Healthy domestic male and female juvenile pigs weighing 42-53 kg were fasted overnight with free access to water. The animals were premedicated with Ketaminol (Ketamine, Intervet, Danderyd, Sweden), $100 \mathrm{mg} / \mathrm{ml}, 0.15 \mathrm{ml} /$ $\mathrm{kg}$, and Rompun (Xylazin, Bayer AG, Leverkusen, Germany), $20 \mathrm{mg} / \mathrm{ml}, 0.1 \mathrm{ml} / \mathrm{kg}$ intramuscularly $30 \mathrm{~min}$ before the procedure. After induction of anesthesia with thiopental $12.5 \mathrm{mg} / \mathrm{kg}$ (Pentothal, Abbott, Stockholm, Sweden) the animals were orally intubated with cuffed endotracheal tubes. A slow infusion of $1 \mu \mathrm{l} / \mathrm{ml}$ fentanyl (Fentanyl, Pharmalink AB, Stockholm, Sweden) in buffered glucose $(25 \mathrm{mg} / \mathrm{ml})$ was started at a rate of $2 \mathrm{ml} /$ min and adjusted if needed. During balanced anaesthesia thiopental (Pentothal, Abbott, Stockholm, Sweden), was titrated towards animal requirements with small bolus doses. Mechanical ventilation was established with a Siemens-Elema 900B ventilator in a volume-controlled mode, adjusted in order to obtain normocapnia (pCO2: 5.0-6.0 $\mathrm{kPa}$ ). The animals were ventilated with a mixture of nitrous oxide (70\%) and oxygen (30\%). The pigs were continuously monitored by electrocardiography (ECG). Arterial blood pressure was measured using an MLT0380/D blood pressure transducer (ADInstruments Inc, Colorado Springs, CO, USA). Heparin (200 IU/kg) was given intravenously at the start of the catheterization. A 12 F introducer sheath (Boston Scientific Scimed, Maple Grove, MN, USA) was inserted into the surgically exposed left femoral vein. A 0.021-inch guide wire (SafeT-J Curved ${ }^{\mathrm{TM}}$, Cook Medical Inc, Bloomington, IN, USA) was inserted into the proximal inferior vena cava through the introducer. Using the guide wire, a 10.7 F Celsius Control $^{\text {TM }}$ catheter (Innercool Therapies Inc, San Diego, CA, USA) was placed into the inferior vena cava with the tip of the catheter at the level of the diaphragm. Body temperature was measured with a temperature probe (TYCO Healthcare Norden AB, Solna, Sweden) placed in the distal part of the esophagus. The catheter and the temperature probe were connected to the Celsius Control and the system was set to maintain a normal pig body temperature of $38.0^{\circ} \mathrm{C}$. A $6 \mathrm{~F}$ introducer sheath (Boston Scientific Scimed, Maple Grove, MN, USA) was inserted into the surgically exposed left carotid artery upon which a 6 F FL4 Wiseguide ${ }^{\mathrm{Tm}}$ (Boston Scientific Scimed, Maple Grove, MN, USA) was inserted into the left main coronary artery. The catheter was used to place a 0.014-inch PT Choice ${ }^{\mathrm{TM}}$ guide wire (Boston Scientific Scimed, Maple Grove, MN, USA) into the distal portion of the LAD. A 3.0-3.5 $\times 15$ mm Maverick monorail ${ }^{\text {TM }}$ angioplasty balloon (Boston Scientific Scimed, Maple Grove, MN, USA) was then positioned in the mid portion of the LAD, immediately distal to the first diagonal branch. A 9 F introducer sheath (Boston Scientific Scimed, Maple Grove, MN, USA) was inserted into the surgically exposed right jugular vein. A $7.5 \mathrm{~F} \mathrm{CCOmbo}^{\text {тм }}$ continuous cardiac output pulmonary artery catheter (Edwards Lifesciences, Irvine, CA, USA) was inserted into a pulmonary artery. Cardiac output was continuously recorded using a Vigilance ${ }^{\mathrm{TM}}$ monitor (Edwards Lifesciences, Irvine, CA, USA). The monitor uses thermal energy emitted by the thermal filament located on the catheter to calculate cardiac output using thermodilution principles. All radiological procedures were performed using an Opescope Pleno ${ }^{\mathrm{TM}}$ imaging system (Shimadzu Corp., Kyoto, Japan).

\section{Experimental protocol}

Ischemia was induced by inflation of the angioplasty balloon for 40 minutes. An angiogram was performed after 
inflation of the balloon and before deflation of the balloon in order to verify total occlusion of the coronary vessel and correct balloon positioning. After deflation of the balloon a subsequent angiogram was performed to verify restoration of blood flow in the previously occluded artery. Twenty minutes before balloon deflation and reperfusion the animals were randomized to treatment with an intravenous bolus dose of ADC-1004 (175 $\mathrm{mg}, \mathrm{n}=8)$ or saline $(0.9 \mathrm{mg} / \mathrm{ml}, \mathrm{n}=8)$. The observers were blinded to the treatment at randomization and analysis. The hearts were explanted four hours after reperfusion and analyzed ex vivo by SPECT and MRI for infarct size, microvascular obstruction and area at risk.

To monitor the plasma concentration of ADC-1004, plasma samples were collected five minutes after administration, at reperfusion, and one, two, three and four hours after reperfusion. Blood levels of leukocytes were measured at baseline and at sacrifice. Plasma levels of Troponin $\mathrm{T}$ were analyzed at baseline and at two, three and four hours after reperfusion. Arterial blood-gases were analyzed at baseline, at reperfusion and one hour after reperfusion. Mean arterial blood pressure, heart rate and cardiac output was measured continuously until one hour after reperfusion.

\section{Dose prediction}

Prior to the in-vivo experiment, the potency of ADC1004 to the C5a receptor was estimated in an in-vitro assay where $\mathrm{C} 5 \mathrm{a}$-induced calcium mobilization was studied by flow cytometry [24]. Pig neutrophils were used and the ability of ADC-1004 to shift C5a-induced concentration-response curves was analysed by Schild-plots, yielding a potency estimate pA2 of $29 \mathrm{nM}$ for ADC1004 to pig neutrophils. It has been reported that clinically effective concentrations correlates closely with the concentration required for $75 \%$ receptor occupancy calculated from the in vitro potency [25], which in the case of ADC-1004, would give an estimated effective concentration of about $90 \mathrm{nM}$. Thus, the aim was to give a dose that kept the plasma concentration at or above 90 $\mathrm{nM}$ throughout the experiment.

\section{Imaging}

Ex vivo imaging of the heart was undertaken according to a previously described protocol $[26,27]$. The MR and SPECT images were analyzed using freely available software (Segment v1.700, Medviso, Lund, Sweden, http:// segment.heiberg.se) [28,29].

\section{Infarct size and microvascular obstruction assessed by ex} vivo MRI

A gadolinium-based contrast agent (Dotarem, gadoteric acid, Gothia Medical AB, Billdal, Sweden) was administered intravenously $(0.4 \mathrm{mmol} / \mathrm{kg}) 30$ minutes prior to explantation of the heart. The heart was explanted 4 hours after initiation of reperfusion. After explantation, the heart was immediately rinsed in cold saline and the ventricles were filled with balloons containing deuterated water. MRI was performed using a $1.5 \mathrm{~T}$ MR scanner (Intera, Philips, Best, the Netherlands). T1-weighted images (repetition time $=20 \mathrm{~ms}$, echo time $=3.2 \mathrm{~ms}$, flip angle $=70^{\circ}$ and 2 averages) with an isotropic resolution of $0.5 \mathrm{~mm}$ covering the entire heart were then acquired using a quadrature head coil. Approximately 200 short-axis images were generated of each heart, yielding a high resolution for infarct size delineation. The endocardial and epicardial borders of the left ventricular myocardium were manually delineated in short-axis images. The volume of the left ventricular myocardium was calculated as the product of the slice thickness $(\mathrm{cm})$ and the area formed by the delineated borders of the epi- and endocardium. The infarct size was determined as the volume of infarcted myocardium $\left(\mathrm{cm}^{3}\right)$. The infarct volume was calculated as the product of the slice thickness $(\mathrm{cm})$ and the area of hyperenhanced pixels $\left(\mathrm{cm}^{2}\right)$ with a signal intensity above the infarction threshold, defined as $>8$ SD above the mean intensity of non-affected remote myocardium. Microvascular obstruction was defined as hypointense regions in the core of the infarction which had signal intensity less than the threshold for infarction. The size of the infarct and microvascular obstruction was expressed as percent of the area at risk (AAR), in order to adjust for any differences in AAR.

\section{Assessment of area at risk by ex vivo SPECT}

Single photon emission computed tomography (SPECT) was used to assess the AAR as percent of left ventricular myocardium (LVM). $1000 \mathrm{MBq}$ of ${ }^{99} \mathrm{~m}_{\mathrm{Tc}}$ tetrofosmin were administered intravenously $10 \mathrm{~min}$ utes before deflation of the angioplasty balloon. Ex vivo imaging was performed with a dual head camera (Skylight, Philips, Best, the Netherlands) at 64 projections (60 s per projection) with a $64 \times 64$ matrix and a zoom factor of 2.19 , yielding a digital resolution of $4.24 \times 4.24 \times 4.24 \mathrm{~mm}$. Iterative reconstruction using maximum likelihood-expectation maximization (MLEM) was performed with a low-resolution Butterworth filter with a cut-off frequency set to 0.6 of Nyquist and order 5.0. No attenuation or scatter correction was applied. Finally short and long-axis images were reconstructed. The endocardial and epicardial borders of the left ventricle that were manually delineated in the MR images were copied to the co-registered SPECT images. A SPECT defect was defined as a region within the MRI-determined myocardium with counts lower than $55 \%$ of the maximum counts in the myocardium [30]. 


\section{Analysis of blood samples}

Plasma levels of Troponin $\mathrm{T}$ were analysed using the Elecsys immunoassay system (Roche Diagnostics Scandinavia, Bromma, Sweden). The white blood cell count (WBC) was measured using a Sysmex XE-5000 automated hematology analyzer (Sysmex Corporation, Kobe, Japan). Blood-gases were analyzed in an automated bench top analyzer (Radiometer Medical ApS, Brønshøj, Denmark). Plasma levels of ADC-1004 were analysed by an ELISA method. In this ELISA, the plates were coated with $2 \mu \mathrm{g} / \mathrm{ml}$ of a mouse mab against ADC-1004. The plates were washed and blocked (3\% milkpowder in PBS $0.05 \%$ Tween 20) and then incubated with plasma samples. ADC-1004 was detected with $3 \mu \mathrm{g} / \mathrm{ml}$ polyclonal rabbit anti-CHIPS N-terminal IgG (IgG produced by immunization of a rabbit with a KLH-coupled synthetic peptide corresponding to CHIPS N-terminal amino acids 1-14) and horseradish peroxidase (HRP) conjugated goat anti-rabbit IgG (Southern Biotech, Birmingham, AL, USA).

\section{Ethics}

The study conforms to the Guide for the Care and Use of Laboratory Animals, US National Institute of Health (NIH Publication No. 85-23, revised 1996) and was approved by the local animal research ethics committee.

\section{Calculation and statistics}

Calculations and statistics were performed using the GraphPad Prism 5.0 software (GraphPad Software Inc., La Jolla, CA, USA). Values are presented as mean \pm SEM. Statistical significance was accepted when $\mathrm{p}<0.05$ (Mann-Whitney test, two-tailed).

\section{Results}

A total of 20 animals were used. Of those, one was not included due to an anomalous coronary anatomy and one died in ventricular fibrillation prior to randomization. Therefore, 18 animals were randomized between control and ADC-1004. One animal in each group died from pulseless electrical activity. Thus, eight animals in each group were included in the final comparison between ADC-1004 and control. All animals in the treatment group experienced ventricular fibrillation (VF) or pulseless ventricular tachycardia (VT). Six of eight animals in the control group experienced VT/VF. All of these were successfully defibrillated to sinus rhythm and spontaneous circulation. Two animals that received ADC-1004 experienced a transient fall in blood pressure immediately after administration of the drug. This did not occur when the administration was carried out over a period of 1.5-3 minutes. No differences were observed between the ADC-1004 group and the control group with respect to the time from reperfusion to explantation (ADC-1004: $286 \pm 2$ vs control: $290 \pm 4$ min, NS).

\section{Imaging and hemodynamic parameters}

ADC-1004 treatment significantly reduced the primary end-point, infarct size relative to the area at risk, by $21 \%$ (ADC-1004: $58.3 \pm 3.4$ vs control: $74.1 \pm 2.9 \%$ AAR, $\mathrm{p}=$ 0.007) (Figure 1A). Infarct size unadjusted for differences in area at risk was also reduced in the ADC-1004 group, although it did not reach statistical significance (ADC-1004: $23.0 \pm 3.0$ vs control: $27.1 \pm 1.4 \%$ LVM, p = 0.16 ) (Figure 2). The area at risk was similar between the groups (ADC-1004: $38.9 \pm 3.7$ vs control: $37.1 \pm$

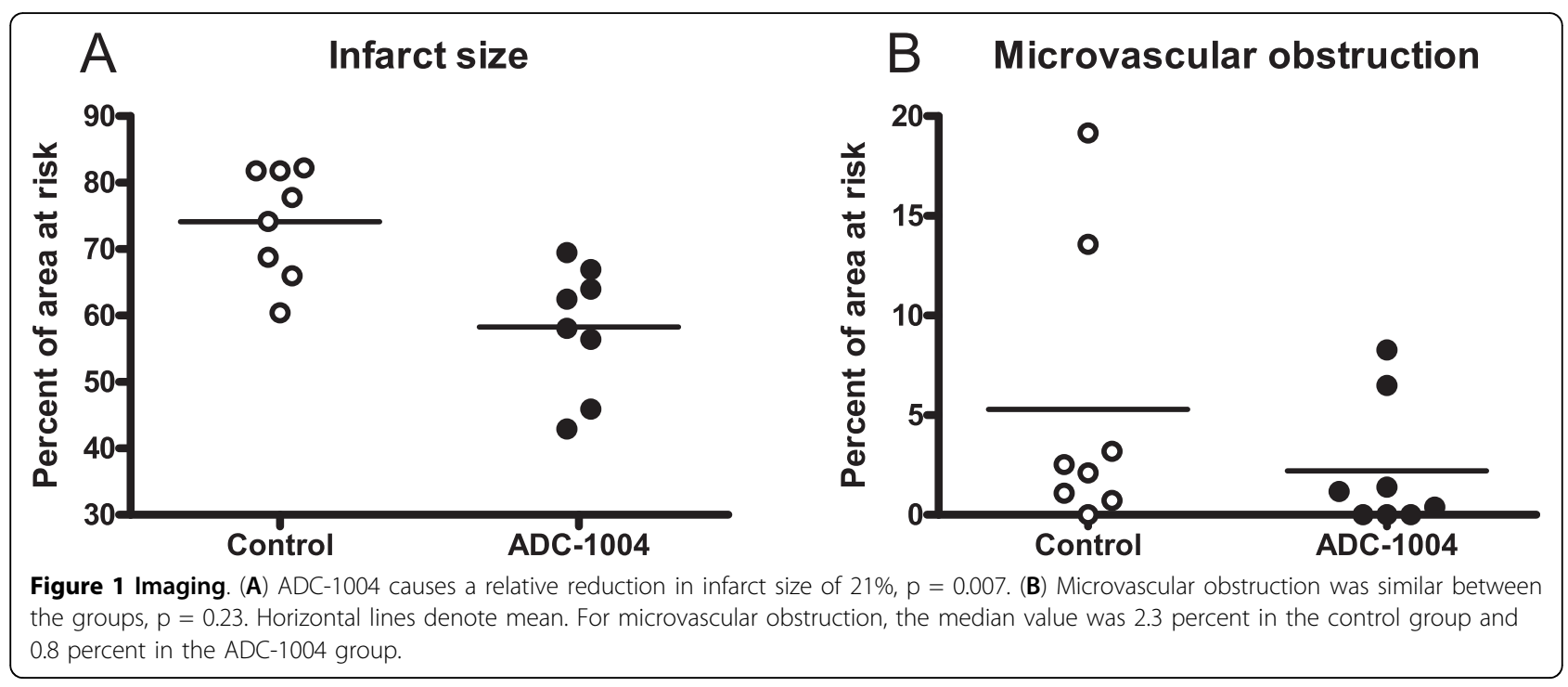




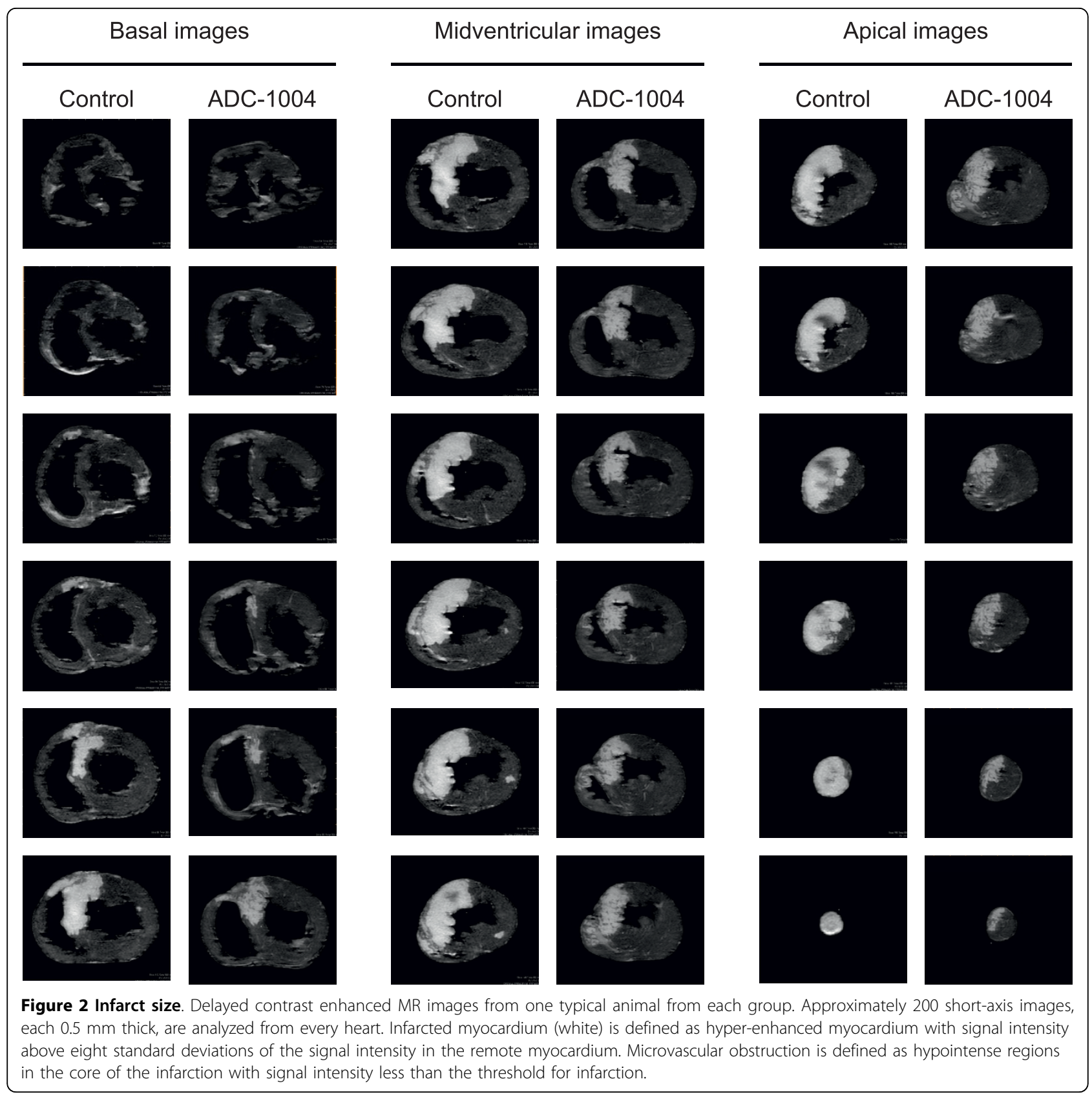

2.7\%LVM, NS). The extent of microvascular obstruction was similar between the groups (ADC-1004: $2.2 \pm 1.2 \mathrm{vs}$ control: $5.3 \pm 2.5 \%$ AAR, $\mathrm{p}=0.23$ ) (Figure 1B). A large variation in microvascular obstruction was observed in both groups. There were no significant differences in hemodynamic parameters between the groups at baseline, at randomization or onwards (Figure 3).

\section{Blood sample analysis}

Mirroring unadjusted infarct size, the area under the curve (AUC) for Troponin $\mathrm{T}$ release was insignificantly reduced by $21 \%$ in the ADC-1004 group (ADC-1004:
$2823 \pm 528$ vs control: $3566 \pm 615, \mathrm{p}=0.38)$. The Troponin $\mathrm{T}$ detection range was $0.03-24 \mu \mathrm{g} / \mathrm{l}$ and in the control group the values were higher than the upper detection limit on a large number of occasions (ADC1004: 3 vs control: 10 occasions).

The mean plasma concentration of ADC-1004 at explantation was $83 \pm 8 \mathrm{nM}$ (Figure 4). The degree of reactive leukocytosis in peripheral venous blood were similar between treatment and control at sacrifice (ADC-1004: $149.5 \pm 12.1$ vs control: $156.5 \pm 15.0$ percent of baseline value, NS). Blood-gases were similar between the groups (Table 1). 

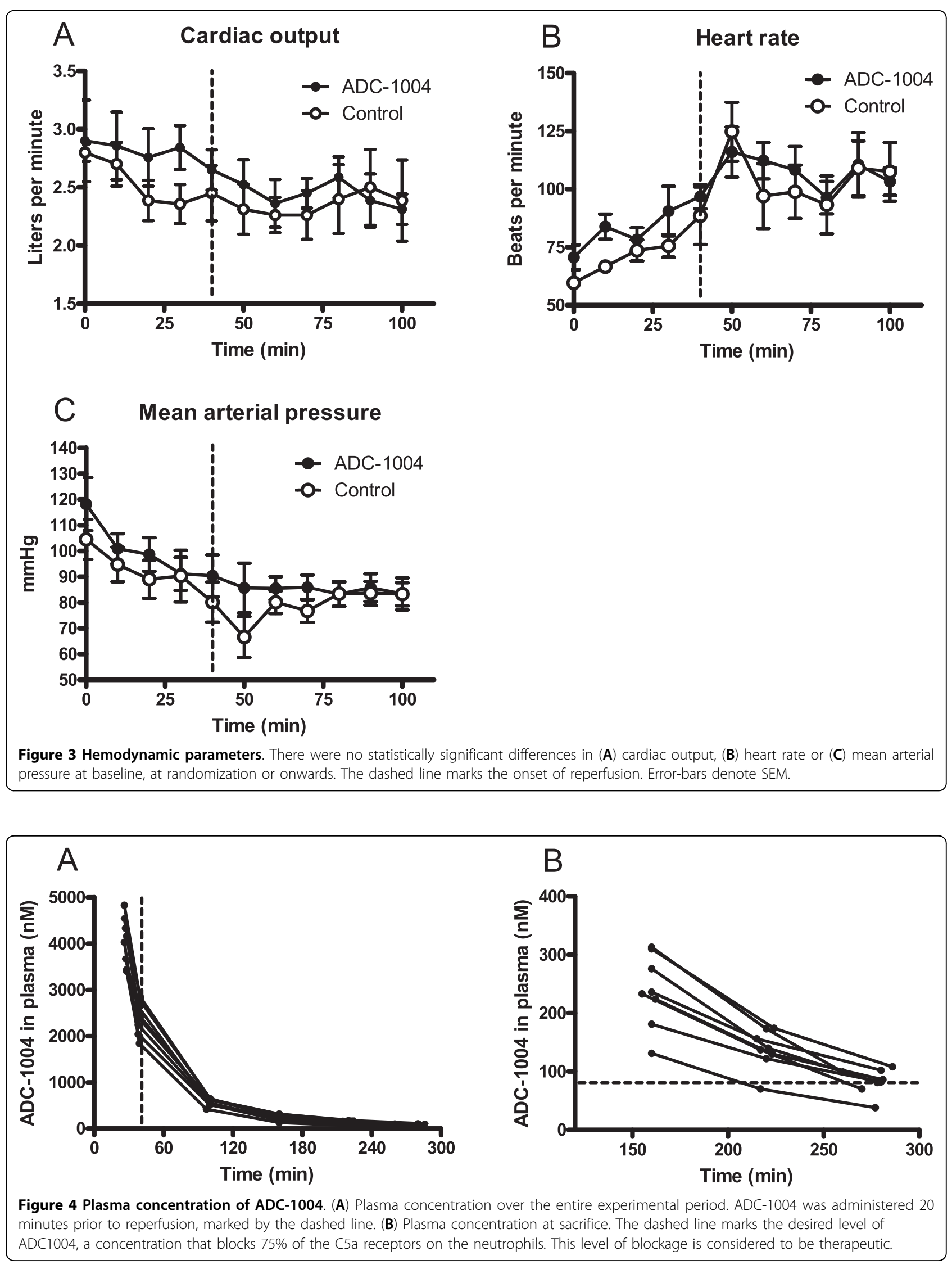
Table 1 Arterial blood-gas data

\begin{tabular}{llll}
\hline & Control & ADC-1004 & P-value \\
\hline $\mathrm{pH}$ - baseline & $7.48( \pm 0.02)$ & $7.49( \pm 0.03)$ & $\mathrm{NS}$ \\
$\mathrm{pH}-40 \mathrm{~min}$ & $7.36( \pm 0.06)$ & $7.41( \pm 0.03)$ & $\mathrm{NS}$ \\
$\mathrm{pH}-100 \mathrm{~min}$ & $7.42( \pm 0.02)$ & $7.43( \pm 0.03)$ & $\mathrm{NS}$ \\
Base excess - baseline & $4.06( \pm 1.48)$ & $5.15( \pm 0.99)$ & $\mathrm{NS}$ \\
Base excess - 40 min & $-1.25( \pm 3.07)$ & $2.85( \pm 1.16)$ & $\mathrm{NS}$ \\
Base excess - 100 min & $1.05( \pm 1.38)$ & $3.25( \pm 1.10)$ & $\mathrm{NS}$ \\
\hline
\end{tabular}

Values are expressed as mean and SEM. pH and base excess were similar between the groups throughout the experiment. The unit for base excess is $\mathrm{mmol} / \mathrm{L}$ and for $\mathrm{pH}-\log _{10}\left\{\mathrm{H}^{+}\right\}$.

\section{Discussion}

This study evaluated the cardioprotective effect of ADC1004 treatment, according to a clinically applicable protocol for ST-segment elevation myocardial infarction (STEMI) with administration before reperfusion. Treatment with ADC-1004 was found to significantly reduce infarct size by $21 \%$ without any hemodynamic side effects.

The porcine model was chosen because it is a large animal model that resembles the human pathophysiology more closely than rodent models, and also allows for a closed chest model utilising human coronary interventional devices. A percutaneous catheter-based approach allows for induction of ischemia with minimum trauma, operation-induced stress and secondary changes in circulatory physiology. The porcine model also offers a possibility of SPECT and MRI for ischemia and infarct size evaluation. Ex vivo MRI allows for achievement of high resolution images of the myocardial infarction and correlates closely to histology [27,31]. MRI and SPECT are also the gold standard methods of evaluation of ischemia and infarct size in clinical practice. Temperature is known to be a major determinant of infarct size [32]. In order to eliminate spontaneous hypothermia as a confounding factor for infarct size development, a normal core body temperature of pigs $\left(38^{\circ} \mathrm{C}\right)$ was maintained. The total ischemia time of 40 min is shorter than in the typical patient with myocardial infarction, which often experience 2-4 hours of ischemia before start of treatment. However, pig infarct progress has been shown to be approximately 7 times more rapid than human [33], suggesting that the current model represents a human STEMI with approximately five hours duration. The faster infarct development seen in pigs is likely due to the lack of collaterals in the porcine coronary circulation.

Treatment with ADC-1004 caused a statistically significant reduction in infarct size of $21 \%$. The extent of microvascular obstruction was similar between the groups, suggesting that the relative contribution of activated neutrophils to the development of microvascular obstruction is less than the contribution of neutrophils to infarct development. The degree of reactive leukocytosis was comparable between the groups, which was to be expected. It is likely that the leukocytes were mobilized during catheterization and early ischemia, prior to administration of ADC-1004. As the mean plasma concentration of ADC-1004 at sacrifice was found to be 83 $\mathrm{nM}$, the aim to keep the plasma concentration at a therapeutic level (i.e. at or above $90 \mathrm{nM}$ ) was met for the major part of reperfusion [25]. Thus, as shown in the dose prediction experiment described in the methods section, the circulating neutrophils were blocked at the C5a receptor in the ADC-1004 group and rendered resistant to $\mathrm{C} 5$ a related activation. The activation has been shown to peak two hours after reperfusion and to rapidly decline thereafter [34]. C5a has also been shown to have a short half-life, with effects resolving within a few minutes [35]. Consequently, a bolus administration of ADC-1004 prior to reperfusion seems to cover the entire therapeutic window for inhibition of C5a-related neutrophil activation. A major advantage with ADC1004 is that, if it is administered before reperfusion, it will protect the circulating neutrophils before they reach the ischemic zone, thereby avoiding even a brief period of activation. There were no significant differences in hemodynamic parameters between the groups, suggesting that ADC-1004 is safe for administration in patients with acute myocardial infarction.

Several other preclinical studies have evaluated the effect of blocking the C5a component, either by blocking the conversion of $\mathrm{C} 5$ to $\mathrm{C} 5 \mathrm{a}$, by neutralising antibodies to C5a or by antagonists of the C5a receptor, over all with findings of cardioprotective effects in animal models [36-39]. Exposure of C5a at a sublytic dose prior to ischemia has also been shown to induce cardioprotection [40], possibly by triggering a preconditioning effect. The preclinical evidence by large, clearly supports a therapeutic possibility in inhibiting C5a related neutrophil activation, which is also in line with the findings in this study.

A few substances have been clinically evaluated recently. The FIRE trial evaluated the effect of inhibition of the neutrophils on infarct size by FX06, a VE-cadherin inhibitor, with the finding of a $58 \%$ reduction in necrotic core zone after five days [41]. However, this finding did not remain after four months [41]. The APEX AMI trial evaluated the humanized monoclonal antibody pexelizumab, that binds the $\mathrm{C} 5$ component of complement, as an adjunct to PCI in improving 30-day mortality from STEMI [42]. In this trial, mortality was unaffected by pexelizumab treatment. Furthermore, even though pexelizumab had been shown to reduce apoptosis and leukocyte infiltration resulting in reduced myocardial injury in an animal model $[39,43]$, pexelizumab treatment initiated prior to reperfusion failed to 
favourably affect infarct size in a phase 2 trial [44]. However, an antibody to $\mathrm{C} 5$ can neither inhibit the C5a that has already been generated nor can it exert its effect prior to the arrival of the substance in the infarct area. A C5a receptor antagonist, on the other hand, offers the advantage of blocking the receptor on the neutrophils prior to the arrival of the neutrophil in the infarct area.

The C5a receptor is also found on cardiomyocytes, and this receptor activates an intracellular signalling cascade involving protein kinase $C$ isoenzyme delta (PKC- $\delta$ ) that may contribute to ischemia/reperfusion injury [45]. The substance KAI-9803 is a PKC- $\delta$ inhibitor that has been shown to reduce myocardial injury in animal models $[46,47]$, and is now in clinical development [48]. Effects of ADC-1004 on cardiomyocytes could mediate some of the cardioprotective effect by reducing PKC- $\delta$ activation, but this needs to be confirmed in future experiments.

\section{Conclusions}

In summary, ADC-1004 treatment, according to a clinically applicable protocol, reduces myocardial ischemiareperfusion injury. ADC-1004 thus represents a novel treatment strategy of myocardial ischemia-reperfusion injury with potential clinical applicability.

\section{Acknowledgements \\ This work was supported by the Swedish Research Council, the Swedish Heart and Lung Foundation and the Vascular Wall program (Lund University Faculty of Medicine). The experiment was also sponsored by Alligator Bioscience AB, Lund, Sweden. We would like to thank Innercool therapies Inc, San Diego, CA, USA for unrestricted loan of the Celsius Control ${ }^{\mathrm{TM}}$ console. We also wish to thank Anna Rosén, Karin Haraldsson and Karin Barchan for laboratory analyses and valuable assistance during animal experiments.}

\section{Author details}

${ }^{1}$ Department of Cardiology, Skåne University Hospital, Lund, Sweden. Department of Clinical Physiology, Skåne University Hospital, Lund, Sweden. ${ }^{3}$ Department of Laboratory Medicine, Skåne University Hospital, Lund, Sweden. ${ }^{4}$ Alligator Bioscience AB, Lund, Sweden.

\section{Authors' contributions}

The authors have contributed as follows: Conception and design (BL, DE and JVDP), animal experimentation (JVDP, SK, PA, MG and GO), image acquisition (JU, MK and HA), analysis and interpretation (JVDP, BL and DE), drafting of the manuscript (JVDP, BL and DE), critical revision for important intellectual content (all authors), final approval of the manuscript (all authors).

\section{Competing interests}

Dr Bengt Larsson is employed by Alligator Bioscience AB, Lund, Sweden. The other authors declare that they have no competing interests.

Received: 4 May 2010 Accepted: 27 September 2010 Published: 27 September 2010

\section{References}

1. Kloner RA: Does reperfusion injury exist in humans? J Am Coll Cardiol 1993, 21:537-545.
2. Ambrosio G, Tritto II: Lethal Myocardial Reperfusion Injury: Does it Exist, Should We Treat It? J Thromb Thrombolysis 1997, 4:69-70.

3. Hearse DJ, Bolli R: Reperfusion induced injury: manifestations, mechanisms, and clinical relevance. Cardiovasc Res 1992, 26:101-108.

4. Kloner RA, Ganote CE, Jennings RB: The "no-reflow" phenomenon after temporary coronary occlusion in the dog. J Clin Invest 1974, 54:1496-1508.

5. Bekkers SC, Yazdani SK, Virmani R, Waltenberger J: Microvascular obstruction: underlying pathophysiology and clinical diagnosis. J Am Coll Cardiol 55:1649-1660.

6. Wu KC, Zerhouni EA, Judd RM, Lugo-Olivieri CH, Barouch LA, Schulman SP, Blumenthal RS, Lima JA: Prognostic significance of microvascular obstruction by magnetic resonance imaging in patients with acute myocardial infarction. Circulation 1998, 97:765-772.

7. Diepenhorst GM, van Gulik TM, Hack CE: Complement-mediated ischemiareperfusion injury: lessons learned from animal and clinical studies. Ann Surg 2009, 249:889-899.

8. Crawford MH, Grover FL, Kolb WP, McMahan CA, O'Rourke RA, McManus LM, Pinckard RN: Complement and neutrophil activation in the pathogenesis of ischemic myocardial injury. Circulation 1988, 78:1449-1458.

9. Pinckard RN, O'Rourke RA, Crawford MH, Grover FS, McManus LM, Ghidoni JJ, Storrs SB, Olson MS: Complement localization and mediation of ischemic injury in baboon myocardium. J Clin Invest 1980, 66:1050-1056.

10. Rossen RD, Michael LH, Kagiyama A, Savage HE, Hanson G, Reisberg MA, Moake JN, Kim SH, Self D, Weakley S: Mechanism of complement activation after coronary artery occlusion: evidence that myocardial ischemia in dogs causes release of constituents of myocardial subcellular origin that complex with human C1q in vivo. Circ Res 1988, 62:572-584.

11. Homeister JW, Satoh P, Lucchesi BR: Effects of complement activation in the isolated heart. Role of the terminal complement components. Circ Res 1992, 71:303-319.

12. Weisman HF, Bartow T, Leppo MK, Marsh HC Jr, Carson GR, Concino MF, Boyle MP, Roux KH, Weisfeldt ML, Fearon DT: Soluble human complement receptor type 1: in vivo inhibitor of complement suppressing postischemic myocardial inflammation and necrosis. Science 1990, 249:146-151.

13. Rezkalla SH, Kloner RA: No-reflow phenomenon. Circulation 2002, 105:656-662.

14. Saraste A, Pulkki K, Kallajoki M, Henriksen K, Parvinen M, Voipio-Pulkki LM: Apoptosis in human acute myocardial infarction. Circulation 1997, 95:320-323.

15. Fernandez HN, Henson PM, Otani A, Hugli TE: Chemotactic response to human $\mathrm{C} 3 \mathrm{a}$ and $\mathrm{C} 5 \mathrm{a}$ anaphylatoxins. I. Evaluation of $\mathrm{C} 3 \mathrm{a}$ and $\mathrm{C} 5 \mathrm{a}$ leukotaxis in vitro and under stimulated in vivo conditions. J Immunol 1978, 120:109-115.

16. Amsterdam EA, Pan HL, Rendig SV, Symons JD, Fletcher MP, Longhurst JC: Limitation of myocardial infarct size in pigs with a dual lipoxygenasecyclooxygenase blocking agent by inhibition of neutrophil activity without reduction of neutrophil migration. J Am Coll Cardiol 1993, 22:1738-1744.

17. Mehta $J$, Nichols WW, Mehta P: Neutrophils as potential participants in acute myocardial ischemia: relevance to reperfusion. J Am Coll Cardiol 1988, 11:1309-1316.

18. Mullane KM, Read N, Salmon JA, Moncada S: Role of leukocytes in acute myocardial infarction in anesthetized dogs: relationship to myocardial salvage by anti-inflammatory drugs. J Pharmacol Exp Ther 1984, 228:510-522.

19. Engler R: Consequences of activation and adenosine-mediated inhibition of granulocytes during myocardial ischemia. Fed Proc 1987, 46:2407-2412.

20. Vinten-Johansen J: Involvement of neutrophils in the pathogenesis of lethal myocardial reperfusion injury. Cardiovasc Res 2004, 61:481-497.

21. Gustafsson E, Rosen A, Barchan K, van Kessel KP, Haraldsson K, Lindman S, Forsberg C, Ljung L, Bryder K, Walse B, et al: Directed evolution of chemotaxis inhibitory protein of Staphylococcus aureus generates biologically functional variants with reduced interaction with human antibodies. Protein Eng Des Sel 2010, 23:91-101.

22. Gustafsson E, Haas PJ, Walse B, Hijnen M, Furebring C, Ohlin M, van Strijp JA, van Kessel KP: Identification of conformational epitopes for 
human IgG on Chemotaxis inhibitory protein of Staphylococcus aureus. BMC Immunol 2009, 10:13.

23. Gustafsson E, Forsberg C, Haraldsson K, Lindman S, Ljung L, Furebring C: Purification of truncated and mutated Chemotaxis Inhibitory Protein of Staphylococcus aureus-an anti-inflammatory protein. Protein Expr Purif 2009, 63:95-101.

24. Gustafsson E: Molecular evolution of a C5aR antagonist against inflammatory disease. PhD Thesis Lund University, Deparment of Immunotechnology 2009.

25. Smith DA, Jones BC, Walker DK: Design of drugs involving the concepts and theories of drug metabolism and pharmacokinetics. Med Res Rev $1996,16: 243-266$.

26. Gotberg M, Olivecrona GK, Engblom $H$, Ugander M, van der Pals J, Heiberg E, Arheden H, Erlinge D: Rapid short-duration hypothermia with cold saline and endovascular cooling before reperfusion reduces microvascular obstruction and myocardial infarct size. BMC Cardiovasc Disord 2008, 8:7.

27. Kim RJ, Fieno DS, Parrish TB, Harris K, Chen EL, Simonetti O, Bundy J, Finn JP, Klocke FJ, Judd RM: Relationship of MRI delayed contrast enhancement to irreversible injury, infarct age, and contractile function. Circulation 1999, 100:1992-2002.

28. Heiberg E, Ugander M, Engblom H, Gotberg M, Olivecrona GK, Erlinge D, Arheden $\mathrm{H}$ : Automated quantification of myocardial infarction from MR images by accounting for partial volume effects: animal, phantom, and human study. Radiology 2008, 246:581-588.

29. Heiberg E, Sjogren J, Ugander M, Carlsson M, Engblom H, Arheden H: Design and validation of Segment-freely available software for cardiovascular image analysis. BMC Med Imaging 10:1.

30. Ugander $M$, Heiberg $E$, Soneson $H$, Engblom $H$, van der Pals J, Erlinge $D$, Arheden $\mathrm{H}$ : A novel method for quantifying myocardial perfusion SPECT defect size by co-registration and fusion with MRI - an experimental ex vivo imaging pig heart study. Scand Cardiovasc J 2008, 42(Suppl):47.

31. Wu KC, Kim RJ, Bluemke DA, Rochitte CE, Zerhouni EA, Becker LC, Lima JA: Quantification and time course of microvascular obstruction by contrastenhanced echocardiography and magnetic resonance imaging following acute myocardial infarction and reperfusion. J Am Coll Cardiol 1998, 32:1756-1764.

32. Schwartz LM, Verbinski SG, Vander Heide RS, Reimer KA: Epicardial temperature is a major predictor of myocardial infarct size in dogs. $J$ Mol Cell Cardiol 1997, 29:1577-1583.

33. Hedstrom E, Engblom H, Frogner F, Astrom-Olsson K, Ohlin H, Jovinge S, Arheden $\mathrm{H}$ : Infarct evolution in man studied in patients with first-time coronary occlusion in comparison to different species - implications for assessment of myocardial salvage. J Cardiovasc Magn Reson 2009, 11:38.

34. Dreyer WJ, Michael LH, Nguyen T, Smith CW, Anderson DC, Entman ML, Rossen RD: Kinetics of C5a release in cardiac lymph of dogs experiencing coronary artery ischemia-reperfusion injury. Circ Res 1992, 71:1518-1524.

35. Martin SE, Chenoweth DE, Engler RL, Roth DM, Longhurst JC: C5a decreases regional coronary blood flow and myocardial function in pigs: implications for a granulocyte mechanism. Circ Res 1988, 63:483-491.

36. Amsterdam EA, Stahl GL, Pan HL, Rendig SV, Fletcher MP, Longhurst JC: Limitation of reperfusion injury by a monoclonal antibody to C5a during myocardial infarction in pigs. Am J Physiol 1995, 268:H448-457.

37. Tofukuji M, Stahl GL, Agah A, Metais C, Simons M, Sellke FW: Anti-C5a monoclonal antibody reduces cardiopulmonary bypass and cardioplegia-induced coronary endothelial dysfunction. $J$ Thorac Cardiovasc Surg 1998, 116:1060-1068.

38. Riley RD, Sato H, Zhao ZQ, Thourani $V H$, Jordan JE, Fernandez $A X, M a X L$, Hite DR, Rigel DF, Pellas TC, et al: Recombinant human complement C5a receptor antagonist reduces infarct size after surgical revascularization. J Thorac Cardiovasc Surg 2000, 120:350-358.

39. Vakeva AP, Agah A, Rollins SA, Matis LA, Li L, Stahl GL: Myocardial infarction and apoptosis after myocardial ischemia and reperfusion: role of the terminal complement components and inhibition by anti-C5 therapy. Circulation 1998, 97:2259-2267.

40. Tanhehco EJ, Lee H, Lucchesi BR: Sublytic complement attack reduces infarct size in rabbit isolated hearts: evidence for C5a-mediated cardioprotection. Immunopharmacology 2000, 49:391-399.

41. Atar D, Petzelbauer P, Schwitter J, Huber K, Rensing B, Kasprzak JD, Butter C, Grip L, Hansen PR, Suselbeck T, et al: Effect of intravenous FX06 as an adjunct to primary percutaneous coronary intervention for acute STsegment elevation myocardial infarction results of the F.I.R.E. (Efficacy of FX06 in the Prevention of Myocardial Reperfusion Injury) trial. J Am Coll Cardiol 2009, 53:720-729.

42. Armstrong PW, Granger CB, Adams PX, Hamm C, Holmes D Jr, O'Neill WW, Todaro TG, Vahanian A, Van de Werf F: Pexelizumab for acute ST-elevation myocardial infarction in patients undergoing primary percutaneous coronary intervention: a randomized controlled trial. Jama 2007, 297:43-51.

43. Thomas TC, Rollins SA, Rother RP, Giannoni MA, Hartman SL, Elliott EA, Nye SH, Matis LA, Squinto SP, Evans MJ: Inhibition of complement activity by humanized anti-C5 antibody and single-chain Fv. Mol Immunol 1996, 33:1389-1401.

44. Granger CB, Mahaffey KW, Weaver WD, Theroux P, Hochman JS, Filloon TG, Rollins S, Todaro TG, Nicolau JC, Ruzyllo W, Armstrong PW: Pexelizumab, an anti-C5 complement antibody, as adjunctive therapy to primary percutaneous coronary intervention in acute myocardial infarction: the COMplement inhibition in Myocardial infarction treated with Angioplasty (COMMA) trial. Circulation 2003, 108:1184-1190.

45. Zhang $H$, Qin G, Liang G, Li J, Barrington RA, Liu DX: C5aR-mediated myocardial ischemia/reperfusion injury. Biochem Biophys Res Commun 2007, 357:446-452.

46. Inagaki K, Chen L, Ikeno F, Lee FH, Imahashi K, Bouley DM, Rezaee M, Yock PG, Murphy E, Mochly-Rosen D: Inhibition of delta-protein kinase C protects against reperfusion injury of the ischemic heart in vivo. Circulation 2003, 108:2304-2307.

47. Ikeno F, Inagaki K, Rezaee M, Mochly-Rosen D: Impaired perfusion after myocardial infarction is due to reperfusion-induced deltaPKC-mediated myocardial damage. Cardiovasc Res 2007, 73:699-709.

48. Bates E, Bode C, Costa M, Gibson CM, Granger C, Green C, Grimes K, Harrington R, Huber K, Kleiman N, et al: Intracoronary KAl-9803 as an adjunct to primary percutaneous coronary intervention for acute STsegment elevation myocardial infarction. Circulation 2008, 117:886-896.

\section{Pre-publication history}

The pre-publication history for this paper can be accessed here: http://www.biomedcentral.com/1471-2261/10/45/prepub

doi:10.1186/1471-2261-10-45

Cite this article as: van der Pals et al:: Treatment with the C5a receptor antagonist ADC-1004 reduces myocardial infarction in a porcine ischemia-reperfusion model. BMC Cardiovascular Disorders 2010 10:45.

\section{Submit your next manuscript to BioMed Central and take full advantage of:}

- Convenient online submission

- Thorough peer review

- No space constraints or color figure charges

- Immediate publication on acceptance

- Inclusion in PubMed, CAS, Scopus and Google Scholar

- Research which is freely available for redistribution

Submit your manuscript at www.biomedcentral.com/submit
C Biomed Central 